\title{
HIGH POWER TEST OF THE FIRST S-BAND RF GUN AT SRRC
}

\author{
C.H. Ho, S.S. Chang, J.P. Chiou, C. S. Fann, K.T. Hsu, S.Y. Hsu, J.Y. Hwang, W.K. Lau, \\ K.K. Lin, T.T. Yang, M.S. Yeh, SRRC, Hsinchu 30077, Taiwan \\ M.L. Hsieh, ITRI, Hsinchu 31040 Taiwan \\ W. Gai, R. Konecny, ANL, Argonne, IL 60439, USA
}

\begin{abstract}
We had constructed an S-band high power rf system at SRRC (Synchrotron Radiation Research Center). It will be used as a test bench of various designs of S-band $\mathrm{rf}$ guns. A $2856 \mathrm{MHz}$ PFN (Pulse Forming Network) system was built to deliver $2 \mu \mathrm{s}, 40 \mathrm{KV}$ voltage pulse at $10 \mathrm{~Hz}$ repetition rate for the XK-5 Klystron. As a quick start, we had fabricated a $2856 \mathrm{MHz}$ single cell rf gun for the high power test. The recent results are reported.
\end{abstract}

\section{INTRODUCTION}

An S-band rf gun test bench had been constructed at SRRC. Through the international collaboration of $\mathrm{rf}$ gun project with U.C. Davis[1], a set of SLAC XK-5 klystron and some capacitors of pulse forming network (PFN) were made available for developing S-band $\mathrm{rf}$ gun in SRRC. We had used these components to build a PFN to deliver $2 \mu \mathrm{s}, 40 \mathrm{KV}$ voltage pulse at $10 \mathrm{~Hz}$ repetition rate for the XK-5 klystron (2856 MHz)[2][3]. The rf power transmission line, and vacuum system were successfully assembled last year[4]. A $2856 \mathrm{MHz}$ single cell rf gun cavity was also fabricated and installed in the system. The recent results from the high power rf conditioning of this gun are presented in this report.

\section{EXPERIMENTAL SET UP}

The schematic layout of the S-band rf gun test bench is given in Fig.1, and a photograph of the whole system is shown in Fig. 2. Basically, the system consists of the gun cavity, waveguide system, and the rf power source system and will be described in more detail in the following sub-sections.

\subsection{Gun Cavity}

We had designed a single cell S-band (2856 MHz) rf gun using the code URMEL. The cavity is a simple pill box type with $81.22 \mathrm{~mm}$ inner diameter and $32.50 \mathrm{~mm}$ cell length. A prototype copper cavity with a flat copper cathode of $15.50 \mathrm{~mm}$ diameter was fabricated, and cold tested in 1999[2]. Then we have constructed an OFE copper cavity of a similar design for the high power test purpose. This OFE copper cavity is without a cathode insert hole. Instead, we will use the central region of the

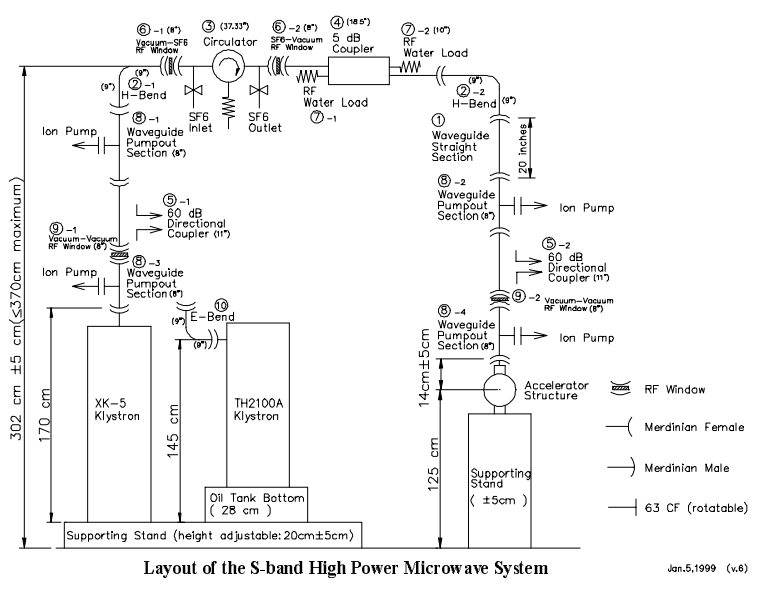

Figure 1: Layout of the S-band rf gun test bench.

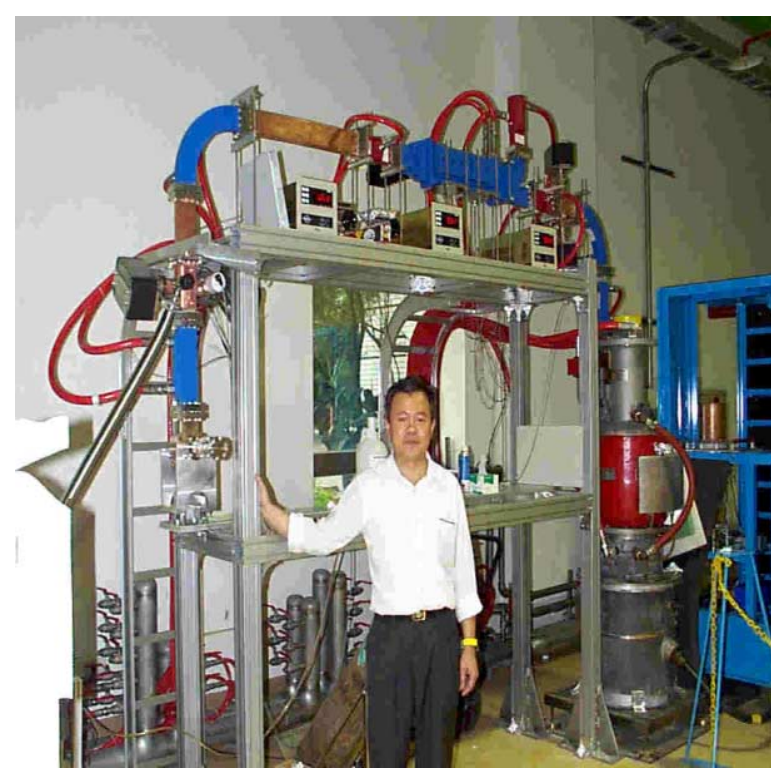

Figure 2: Photograph of the system.

copper wall as the photocathode in the future. A ceramic gap and a tee with an ion pump $(20 \mathrm{l} / \mathrm{sec})$ at the side port are connected to the exit end of the gun cavity. The dark current is monitored by a fast current transformer mounted outside the ceramic gap. A blank flange covering the end tube of the tee will also be used as a 
Faraday cup to measure the beam current. The side view of the gun assembly is shown in Fig. 3.

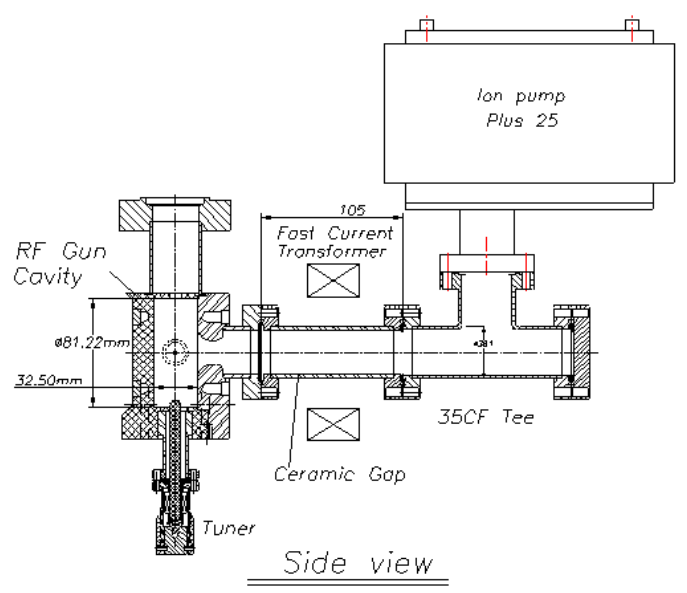

Figure 3: Side view of the gun assembly.

The cavity is equipped with a tuner and a field monitor. The tuning sensitivity of the tuner is around 0.9 $\mathrm{MHz} / \mathrm{mm}$ and $0.4 \mathrm{MHz} / \mathrm{turn}$. Figure 4 shows the transmission coefficient $\left(\mathrm{S}_{21}\right)$ from the filed monitor and the reflection coefficient $\left(\mathrm{S}_{11}\right)$ of the cavity. The measured unloaded quality factor is 9928 for the brazed cavity. The coupling coefficient is 1.2 (over coupled). The cavity inner surface was polished at ITRI and the surface roughness is around $0.02 \mu \mathrm{m}$.

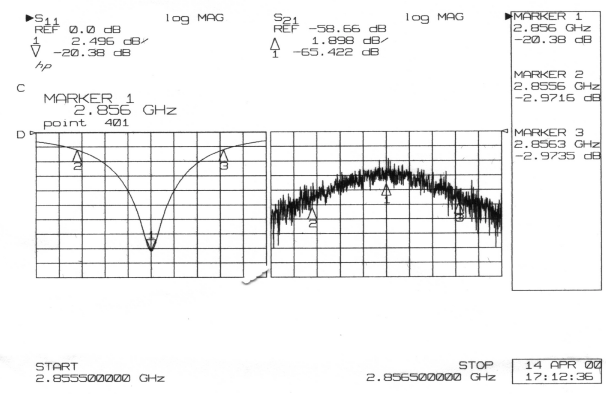

Figure 4: Reflection $\left(\mathrm{S}_{11}\right)$ and transmission coefficients.

\subsection{Waveguide system}

The rf power transmission line consists of two $60 \mathrm{~dB}$ dual directional couplers (one is next to the XK-5 klystron and the other is next to the gun cavity), two pumpout waveguide sections, two $\mathrm{H}$-plane bends, one circulator (30 dB isolation) with two rf windows on both ends, and straight WR-284 waveguide sections. The circulator is pressurized with $\mathrm{SF}_{6}$ to $35 \mathrm{psig}$. Four little ion pumps $(201 / \mathrm{sec})$ are used in both pumpout sections to keep the vacuum pressure around $7.5 \times 10^{-9}$ mbar before the rf power conditioning. A fast trip circuit consisting of the operational amplifier, comparator, and programmable logic circuit is used to protect the system. The circuit response time is $500 \mathrm{nsec}$. The vacuum trip level is set at $4 \times 10^{-7} \mathrm{mbar}$, and the reflected power trip level is set at around $1 \%$ of the peak power.

\subsection{RF power source system}

The rf power source consists of a $1 \mathrm{~kW}$ driver klystron (Thomson tube TH2047) system, a 16 MW XK-5 klystron and the associated PFN system. The PFN functional block diagram is given in Fig. 5. An EMI$303 \mathrm{~L}-50 \mathrm{kV}$ constant current power supply is used (to replace the Spellman SR-6 module) as the high voltage (HV) charging power supply to feed the capacitor bank of PFN. Triggering of PFN pulse is determined by the timing system of $\mathrm{rf}$ gun. The PFN pulse is further amplified at the entrance of XK-5 with a 1:12 ratio pulsed transformer. XK-5 cathode heater and grid bias are provided by supporting electronics. The final HV pulse applied to the klystron is monitored with a voltage divider. RF signal is first chopped and integrated with protection circuit before sending into XK-5. Then, the high power $\mathrm{rf}$ signal is transmitted to rf gun cavity through WR-284 rectangular waveguide system. The technical specification and more details about this home made modulator are given in references [2] and [3].

Layout of RF Gun PFN Functional Block Diagram

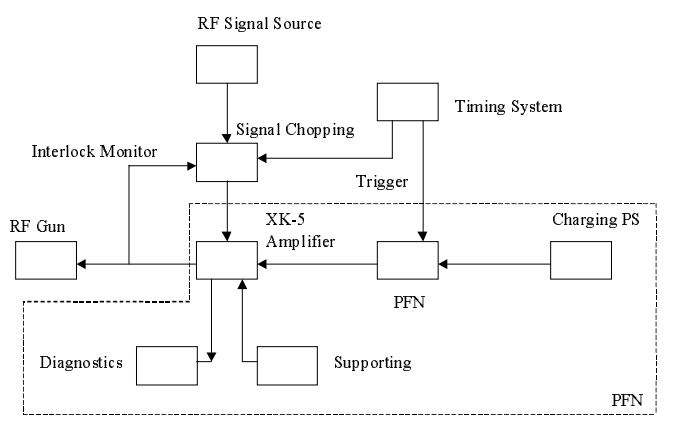

Figure 5: Layout of the PFN functional block diagram.

\section{RECENT TEST RESULTS}

The high power rf conditioning of the gun had been underway. We started at $3 \mathrm{~kW}$ rf power for tuning the cavity resonant frequency (at $23^{\circ} \mathrm{C}$ ) by minimizing the reflected power from the cavity. Several improvements had been made to expedite the conditioning work. The charging resistors of the PFN were re-arranged to sustain $10 \mathrm{~Hz}$ repetition rate instead of single shot basis. The matching resistor of the PFN was adjusted to increase the output voltage. An additional ion pump (20 1/sec) was installed in front of gun exit to improve the vacuum. 
A Fast Current Transformer (BERGOZ FCT-082-05:1) was placed around the ceramic gap at the gun exit to measure the dark current. We also noticed the rf power signal noise was reduced significantly after replacing the RG58 cable with RG214 cable. All crystal diodes for measuring the $\mathrm{rf}$ power were all calibrated using the HP8665B synthesized signal generator, HP 435B rf power meter, and TDS3054 oscilloscope. All attenuators, connectors and cables were calibrated using the HP8510C network analyzer. During the conditioning, the vacuum was usually kept under $5 \times 10^{-8}$ mbar. The occurrences of breakdown, which is witnessed by the distortion of the reflected power and dark current signal, were also kept to minimum as possible. Figure 6 shows the forward rf power to gun cavity (top curve) at around 4.3 MW, reflected power from the cavity (second to top curve), forward power from XK-5 klystron (second to bottom curve), and the dark current signal (bottom curve). The bottom curve in Fig. 7 is the signal from the field monitor of gun. After 50 hours (spreading over a period of 3 weeks) of $\mathrm{rf}$ processing, the forward power into cavity is over $6 \mathrm{MW}$. The electric field gradient on cathode center is estimated to be over $150 \mathrm{MV} / \mathrm{m}$.

A solenoid for electron beam focusing is under construction. Further rf conditioning with solenoid and more $\mathrm{rf}$ power into the cavity will be resumed soon to find out the breakdown limit of this gun. A solid state laser system will be the next target to plan for the production of the photo-electrons out of the gun.

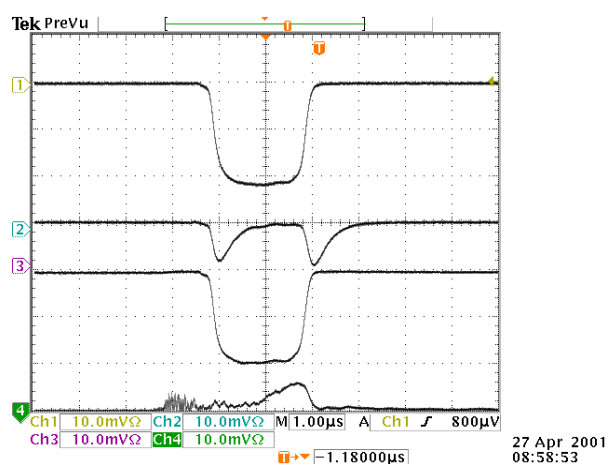

Figure 6: Cavity forward power signal (Ch.1, top), reflected power signal (Ch.2, second to top), klystron forward power signal (Ch.3, second to bottom), and dark current signal (Ch.4, bottom).

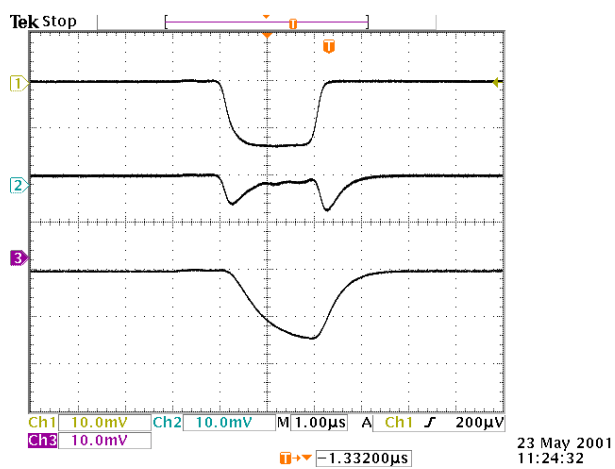

Figure 7: Forward power signal (top) and reflected power signal (middle) and field monitor signal (bottom) of the gun cavity.

\section{SUMMARY}

A single cell $\mathrm{rf}$ gun cavity had been fabricated and installed. The $\mathrm{rf}$ power transmission line was successfully assembled. The vacuum of the whole system is kept around $7.5 \times 10^{-9} \mathrm{mbar}$ before rf processing. The cavity resonant frequency is well tuned. The whole new $\mathrm{rf}$ system is working properly. The $\mathrm{rf}$ power was increased gradually to be over $6 \mathrm{MW}$ in 50 hours (spreading over a period of 3 weeks). The electric field gradient on cathode center is estimated to be over 150 $\mathrm{MV} / \mathrm{m}$.

A solenoid for electron beam focusing is under construction. Further rf conditioning with solenoid and more rf power into the cavity will be resumed soon to find out the breakdown limit of this gun.

\section{ACKNOWLEDGEMENTS}

This work was supported in part by the National Science Council (Taiwan) under contract No. NSC882112-M-213-007.

\section{REFERENCES}

[1] C.H. Ho, et. al., "The Design and Fabrication of an X-Band RF Gun", AAC'96, Lake Tahoe, California, 1996 (AIP Conf. Proc. 398, p.705).

[2] C.H. Ho, et. al., "The Status of S-Band RF Gun System at SRRC", Proc. 1999 Particle Accelerator Conf. (New York, 1999), p.2009.

[3] J.P. Chiou, K.K. Lin, C.H. Ho, "Construction of XK-5 Klystron Pulse Forming Network for S-Band RF Gun", SRRC/RF/2000-01 (SRRC internal report, March 14, 2000).

[4] C.H. Ho, et. al., "The Initial Results from the SBand RF Gun at SRRC", Proc. Seventh European Particle Accelerator Conf. (Vienna, Austria, 2000), p.1651. 